\title{
SMART TECHNICAL SKILL ASSESSMENT ANDROID APPLICATION USING MACHINE LEARNING
}

\author{
Ishwar Kalbandi \\ Project Guide \\ Dept of Computer Engineering \\ DYPIEMR Akurdi, Pune
}

\author{
Ajinkya Bhujbal \\ Dept of Computer Engineering \\ DYPIEMR Akurdi, Pune
} $(S P P U)$

\author{
Mohammad Suhaib Ahmed \\ Dept of Computer Engineering \\ DYPIEMR Akurdi, Pune \\ (SPPU) \\ Nikhunj Saraf \\ Dept of Computer Engineering \\ DYPIEMR Akurdi, Pune \\ (SPPU)
}

\author{
Rohan Atale \\ Dept of Computer Engineering \\ DYPIEMR Akurdi, Pune
}

(SPPU)

\begin{abstract}
This project is for every programmer whether they are absolute beginners or a pro at coding. There are a lot of websites that teach programming languages or provide you with the platform to solve programming language. But they often ignore the personality and skill level of the programmer. If you sign up for the first time you have to do all the basic stuff first in order to get to your level. We propose a system where we test the programmer first with basic to hard programming questions in the language of their choice and then software decides the skill level of the programmer. the course and the problem will be set according to the programmer skills and it will change accordingly with the growth.
\end{abstract}

Keywords-Skill Assessment, Machine Learning, Formative Assessment, Artificial Algorithm, Mobile Application

\section{INTRODUCTION}

Education is moving far from ancient rows of scholars gazing at a similar textbook whereas a teacher lectures from the front of classroom. Today's school rooms aren't merely evolving to use additional technology and digital resources; they additionally finance in machine learning. [1] Matthew Lynch (2018) in his article emphasize and addressed ways on how machine learning will improve education. He stated that Personalized learning refers to instruction during which the pace of learning and therefore the tutorial approach are optimized for the needs of each learner. [2] Sukant Khurana (2018) in his article explain the concept of Personalized Learning and how we can make use of Artificial Intelligences to our benefits, to induce a concept of what personalized learning is, try and imagine a room that doesn't have a "one size fits all" approach to education. The teacher doesn't lead all students through similar lessons. Instead, the teacher guides every student on a personalized journey. The what, when, wherever and the way of learning is ready-made to satisfy every student's strengths, skills, needs, and interests. personalized learning doesn't replace associate degree IEP, a 504 arrange or intervention programs. [3]. Amanda Morin (2017) in her article on Personalized Learning: What you need to know emphasized on how personalized learning is in school curriculum during this project, we have a tendency to planned a system wherever the scholar will develop their ability victimization our personalized skill assessment tool and learn at their own pace. learning: [2]

There are a few key approaches toward personalized

a. Adaptive learning: technology who assign human or digital resources to learners to supported their distinctive wants.

b. Individualized learning: the pace of learning is adjusted to fulfill the needs of individual students.

c. Differentiated learning: the approach to learning is adjusted to satisfy the wants of individual students.

d. Competence-based learning: learners advance through a learning pathway supported their ability to demonstrate competence, also because the applying and creation of information in conjunction with side skills and tendencies

\section{LITERATURE SURVEY}

1. Baolin Yi; Dujuan Zhang [4] (2017), introduce a brand-new approach to personalized Learning Model underneath informatization surroundings. thanks to the influence of scientific discipline and science, customized learning has bit by bit drawn the eye of the many 
researchers. the aim of this paper is to analysis a suitable customized learning technique for learners. during this paper, we have a tendency to perform a study by literature review from four aspects. Firstly, we have a tendency to construct a learner model supported learner's learning vogue and psychological feature ability.

2. Guilherme, A. AI [5], describes the teacher and student relations. A process side of our trendy age is our tenacious belief in technology altogether walks of life, not least in education. It might be argued that this infatuation with technology or 'techno-philia' in education has had a deep impact within the classroom changing the connection between teacher and student, moreover as between students; that's, these relations became progressively more I-it so I-Thou primarily based as a result of the capability to make bonds, the amount of connectedness between teacher and students, and between students has either shrunken or become impaired by the increasing technologization of education.

3. Er, Erkan. (2012) [6], describes a way to characteristic At-risk Students using Machine Learning Techniques, a model for predicting students' performance levels is projected that employs three machine learning algorithms: instance-based learning Classifier, Decision Tree and Naïve Thomas Bayes. additionally, three decision schemes were wont to mix the results of the machine learning techniques in several ways to analyze if higher classification performance might be achieved. The study conducted by Kotsiantis et al [1] is one of the initial studies that investigated the applying of machine learning techniques in distance learning for dropout prediction. during this study, time-invariant and time-varying information was enclosed and whole six machine learning techniques were utilized, that square measure call Trees, Neural Networks, Naïve Thomas Bayes algorithmic rule, Instance-Based Learning Algorithms, supplying Regression and Support Vector Machines. The vital conclusion of this study is that Naïve Thomas Bayes algorithmic rule is extremely booming within the prediction of dropouts; it predicts with $83 \%$ accuracy.

4. In 2007, Ashford, S. J. (1986)[7], in their work emphasize and addressed Formative Assessment for college students and lecturers State cooperative (FAST SCASS) (7) of the Council of Chief State Officers with national and international researchers in formative assessment known Five attributes of the formative assessment method from the literature. they're as follows:

I. Learning progressions ought to clearly articulate the sub-goals of the final learning goal.

II. Learning goals and criteria for fulfillment ought to be clearly known and communicated to students.
III. Students ought to be supplied with evidencebased feedback that's joined to the meant tutorial outcomes and criteria for fulfillment.

IV. Each self- and peer-assessment are necessary for providing students a chance to assume metacognitively concerning their learning.

V. A schoolroom culture within which lecturers and students are partners in learning ought to be established

5. Hattie, J., \& Timperley, H. (2007). [8] describes in his Review of instructional analysis March 2007 of the facility of Feedback, Feedback is one among the foremost powerful influences on learning and action, however, this impact is often either positive or negative. Its power is often mentioned in articles concerning learning and teaching, however amazingly few recent studies have consistently investigated its which means. this text provides an abstract analysis offered back and reviews the proof associated with its impact on learning and action. This proof shows that though. feedback is among the main influences, the kind of feedback and therefore the manner it's given are often differentially effective.

TABLE 2

\begin{tabular}{lcccc}
$\begin{array}{l}\text { TABLE 2 } \\
\text { Summary of effect sizes relating to feedback effects }\end{array}$ & $\begin{array}{c}\text { Number of } \\
\text { meta-analyses }\end{array}$ & $\begin{array}{c}\text { Number of } \\
\text { studies }\end{array}$ & $\begin{array}{c}\text { Number of } \\
\text { effects }\end{array}$ & $\begin{array}{c}\text { Effect } \\
\text { size }\end{array}$ \\
\hline Variable & 3 & 89 & 129 & 1.10 \\
Cues & 74 & 4,157 & 5,755 & 0.95 \\
Feedback & 1 & 19 & 19 & 0.94 \\
Reinforcement & 1 & 91 & 715 & 0.64 \\
Video or audio feedback & & & & \\
Computer-assisted & 4 & 161 & 129 & 0.52 \\
instructional feedback & 8 & 640 & 121 & 0.46 \\
Goals and feedback & 3 & 100 & 61 & 0.42 \\
Student evaluation feedback & 25 & 1,149 & 1,040 & 0.37 \\
Corrective feedback & 5 & 178 & 83 & 0.34 \\
Delayed versus immediate & 3 & 223 & 508 & 0.31 \\
Reward & 8 & 398 & 167 & 0.24 \\
Immediate versus delayed & 1 & 89 & 210 & 0.20 \\
Punishment & 11 & 388 & 4,410 & 0.14 \\
Praise & 1 & 40 & 23 & -0.04 \\
Programmed instruction & & & & \\
& & & &
\end{tabular}

A model of feedback is then planned that identifies the actual properties and circumstances that build it effective, and a few usually thorny problems are mentioned, together with the temporal order of feedback and therefore the effects of positive and feedback. Finally, this analysis is employed to recommend ways in which within which feedback is often wont to enhance its effectiveness in lecture rooms.

6. Heritage, M. (2007). [9] describes what the skillful use of formative assessment would seem like. in What Do lecturers ought to recognize and Do? She explained that Formative assessment if used effectively, will give lecturers and their students with the knowledge they have to maneuver to move forward. however, once over 100 years of exhortations and a big body of analysis on the subject, the concept that assessment and teaching are reciprocal activities remains not firmly placed within the observe of educators. Instead, assessment is usually viewed as one thing in competition with teaching, instead of as associate integral a part of teaching and learning. the 
educational progression ought to clearly articulate the sub-goals that represent progress toward the ultimate goal. Most state standards, by themselves, don't give a transparent progression for understanding wherever students are relative to desired goals.

In fact, several state standards don't even give a transparent image of what learning is anticipated. Developing learning progressions toward standards could be an essential component of formative assessment. Learning progressions give a large image of what's to be learned, and that they facilitate lecturers find students' current learning standing on the time on that student's square measure expected to progress.

7. Pellegrino, James. (2005). [10] who works in the Department of Psychology University of Illinois at Chicago, USA said in his paper on "The Challenge of Knowing What Student Know", Educators assess students to learn about what they know and can do, but assessments do not offer a direct pipeline into a student's mind. Assessing student knowledge and educational outcomes are not as straightforward as measuring height or weight; the attributes to be measured are mental representations and processes that are not outwardly visible. Thus, an assessment is a tool designed to observe students' behavior and produce data that can be used to draw reasonable inferences about what students know. Deciding what to assess and how to do so is not as simple as it might appear. Existing guidelines for assessment design emphasize that the process should begin with a statement of the purpose for the assessment and a definition of the content domain to be measured (AERA et al., 1999; Millman \& Greene, 1993).

In summary, Mislevy et al. provide us with a comprehensive model for educational assessment that clearly outstrips the current knowledge base. Furthermore, it may also contain a level of specificity that lacks conceptual and empirical justification. Much more evidence will be needed about the necessity, sufficiency, and utility of what they propose. Even so, the broader rationale for their system contains many important implications for assessment design, practice, and policy. We have a considerable distance to travel in meeting the scientific, practical and political challenges implied by evidence-centered design systems. Nonetheless, even small steps along the path of such systems will undoubtedly lead to significantly improved educational assessment.

8. Wiliam, Dylan. (2006). [11] ETS wrote in his paper on Formative assessment: obtaining the main target right concerning the Writing in 1967, Michael Scriven steered 2 roles that analysis may play. On the one hand, "it's going to have a task within the on-going improvement of the curriculum" (Scriven, 1967 p.41) whereas in another role, " the analysis method could serve to alter directors to come to a decision whether or not the whole finished information, refined by use of the analysis method in its initial role, represents a sufficiently vital advance on the obtainable alternatives to justify the expense of adoption by a college system" (pp. 41-42). He then planned "to use the terms 'formative' and 'summative' analysis to qualify analysis in these roles."

What makes Associate in Nursing assessment formative, therefore, isn't the length of the circuit, nor wherever it takes place, nor UN agency carries it out, nor even UN agency responds. The crucial feature is that proof is elicited, taken in terms of learning wants, and accustomed to create changes to higher meet that learning wants.

\begin{tabular}{lll}
\hline Type & Focus & Length \\
\hline $\begin{array}{l}\text { Long-cycle } \\
\begin{array}{l}\text { Medium-cycle } \\
\text { Short-cycle }\end{array}\end{array}$ & $\begin{array}{l}\text { between instructional units } \\
\text { between lessons } \\
\text { within a single lesson }\end{array}$ & $\begin{array}{l}\text { four weeks to one year or more } \\
\text { one day to two weeks } \\
\text { five seconds to one hour }\end{array}$ \\
\hline \multicolumn{3}{l}{ Table 1: Types of formative assessment }
\end{tabular}

All the papers during this special issue highlight these aspects to a bigger or lesser extent. The analysis by Ruiz-Primo and Aracelli shows that the lecturers who most systematically elicit the proper forms of data (conceptual eliciting questions), who have ways in which of decoding the students' responses in terms of learning wants, and who will use this data to adapt their instruction, generate higher levels of student accomplishment.

Taken as a full, the papers during this issue build vital contributions to our understanding of however troublesome it's doubtless to be to enhance teachers' use of formative assessment methods. above all, they counsel that whereas the supply of high-quality tools is also a necessary condition, it's in no way a comfortable condition for the development of formative assessment. Tools for formative assessment can solely improve formative assessment practices if lecturers will integrate them into their regular schoolroom activities. In alternative words, the task of rising formative assessment is considerable, if not chiefly, regarding teacher skilled development.

9. Ibtehal Talal Nafea [12] wrote a paper on topic Machine Learning in Education Technology wherever he talks regarding the role of metric capacity unit in Education by describing the however it will remodel learning to a good height. Customized and personalized learning (14) - Machine learning is versatile enough to cater to all or any students despite their learning speeds.

By creating the use of algorithms that learn the way the scholar consumes data, machine learning permits the learner to maneuver ahead solely when they need actually grasped the previous content. This method ensures that no student is unnoticed or left behind. this is often true notwithstanding they're the sole one in school that has not however understood the content. The machine learning system conjointly permits lecturers to separately monitor 
student and facilitate them those areas wherever they're deficient.

This contrasts with the standard academic technique, that focuses on one-size-fits-all management wherever everybody in school is instructed constant manner. this kind of learning may be found within the EdTech and MagicBox learning systems

The future work on machine learning, particularly within the education context, shall witness the event of a lot of subtle AI tools. There square measure multiple prospects for coming up with complicated chatbots which will improve the sophistication of virtual assistants. This development shall foster a lot of human interactions which will replace emails and text messages. Already, plans square measure current for developing on-line virtual assistants named "Amy" or "Andrew" at x.ai to schedule conferences with each tutor and learners. AI not to mention machine learning that includes deep learning and linguistic communication process is projected to travel level higher by incorporating a lot of subtle systems laced with capabilities to adapt, learn and predict systems with utmost autonomy. the longer term works on these systems shall incorporate a mixture of advanced algorithms and embedded huge knowledge sets.

10. Kotsiantis, S.B [13] aforementioned in his Paper Use of Machine learning Techniques for academic purposes: a call network for prediction students' grades Use of machine learning techniques for academic purposes (or academic knowledge mining) is AN rising field aimed toward developing ways of exploring knowledge from machine academic settings and discovering purposeful patterns.

The hold on knowledge (virtual courses, e-learning log file, demographic and tutorial knowledge of scholars, admissions/registration information, then on) may be helpful for machine learning algorithms. As a lot of and a lot of students enter on-line learning environments, databases regarding student access and study patterns can grow. Having data like check scores and alternative student data obtainable electronically will offer tutors with powerful tools for decision-making. we tend to hope that the data made by such call support tools may be usefully applied by tutors to attenuate the number of scholars United Nations agency square measure probable to fail by providing them with further teaching material or the other support. methods in usage of machine learning techniques for academic proposes embrace classification and regression algorithms, association rules, serial pattern analysis, likewise as cluster and internet mining (Baker and Yacef 2009).

In e-learning, classification has been used for grouping students as hint-driven or failure driven and finding students' common misconceptions (Yudelson et al. 2006); distinctive learners with very little motivation and finding remedial actions so as to lower drop-out rates
(Cocea and Weibelzahl 2006) and for predicting course success (Hamalainen and Vinni2006) In this Paper we tend to learn however we will use totally different machine learning to our advantage within the planned project.

\section{EXISTING SYSTEM}

There are so many web-based and android based applications which are, one way or the other related to quiz, however, there are only a few that help in learning and contribute to the skill enhancement of the user. Most of the available applications aim at having fun or entertainment. Among the many applications, we review some Web based and Android based applications that are quite famous and are successful in terms of number of users and downloads.

Following is the detail of some quiz systems:

\section{JAGRAN Josh Computer General Knowledge Quiz:}

Computer general knowledge Quiz section may be a repository of Multiple-Choice Questions that assist you to remember about the evolving nature of competitive exams, this quiz is about subjects associated with the pc science field. It's a general computer quiz. This quiz is useful for the preparation of any computer field trial. during this app, questions are given alongside four choices, and at the top the right choice is additionally given. After the test, students can check their level of preparation through the quiz app.

\section{EDU zip The Knowledge Hub:}

It is a Computer Science Quiz. It contains MCQs and answers with description and examples. Operating System, Database, Software Engineering, Computer Networks, Digital Electronics are some subfields present in this quiz. These Computer Science MCQs will help users for interviews and competitive exams.

Although there are many sites and android apps that focus on the quiz, there are limited applications with focus on learning or improving knowledge in the academic area. Most of the applications are entertainment-based with little focus on the educational side. There are many limitations with the present systems mentioned above. To counter such limitations, we propose a user-friendly application, namely "Sment", which mainly aims on gaining academic knowledge and assessing his skills. It also provides a learning path to users.

\section{PROPOSED APPROACH}

In proposed work, we developed a system that perfectly assesses the users and provides them with the learning path personalized to them according to their goals 
and skills they currently have and what they want to achieve in the future. We ask each user some certain types of questions first to identify his profile and get a better understanding of his future goals.

After that pre-questionnaire, the user can give a generalized test to check his skills in various different fields in the computer and after the test, we will display his knowledge graph in each of these fields and what he should focus on. The user can take more specialized tests in a particular subject to assess his hold on the subject. Our System helps users to provide a clear path by removing all the clutter. With the vast information we have on the internet we are more confused than educated.

Because we need an algorithm for classification of a user's skills based on his performance, we used classification with keras for classification problem and content-based filtering for recommendation problem.

A. Algorithms Used

1. Classification with Keras:

Classification is a type of supervised machine learning algorithm used to predict a categorical label. A few useful examples of classification include predicting whether a customer will churn or not, classifying emails into spam or not, or whether a bank loan will default or not. The basic architecture of the deep learning neural network, which we will be following, consists of three main components. Keras is a high-level neural networks API, written in Python, and can run on top of TensorFlow, CNTK, or Theano. The advantages of using Keras emanates from the fact that it focuses on being user-friendly, modular, and extensible. Following are the steps which are commonly followed while implementing models with Keras.

Step 1 - Loading the required libraries and modules Step 2 - Loading the data and performing basic data checks.

Step 3 - Creating arrays for the features and the response variable

Step 4 - Creating the Training and Test datasets

Step 5 - Define, compile, and fit the Keras classification model

Step 6 - Predict on the dataset and compute evaluation metrics

2. Content-based filtering:

Content-based filtering algorithms are given user preferences for items and recommend similar items based on a domain-specific notion of item content. This approach also extends naturally to cases where item metadata is available Recommender systems are active information filtering systems that personalize the information coming to a user based on his interests, relevance of the information, etc. Recommender systems are used widely for recommending movies, articles, restaurants, places to visit, items to buy, and more. A recommender system has to decide between two methods for information delivery when providing the user with recommendations:

1.Exploitation. The system chooses documents similar to those for which the user has already expressed a preference.

2.Exploration. The system chooses documents where the user profile does not provide evidence to predict the user's reaction

\section{SYSTEM ARCHITECTURE}

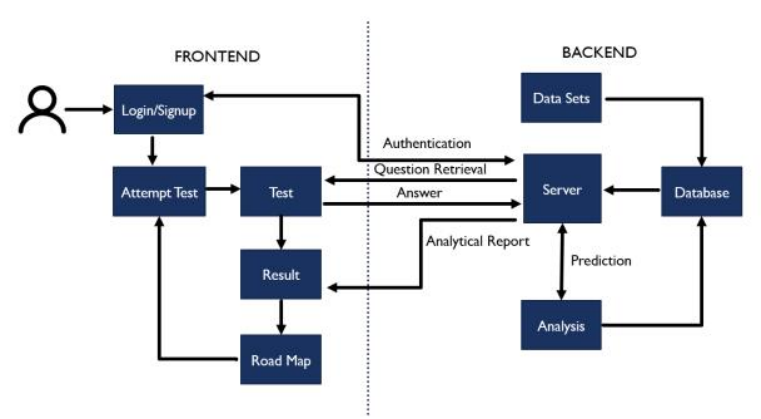

The user will be allowed first to login/register in to the system. After the login the user will be asked to give the survey test in which is used to assess the user's goals. After that the user will be allowed to give the assessment test in the technology he wants to and based on the test results are generated which are used to recommend a learning path to user.

\section{IMPLEMENTED SYSTEM}

Sment is an android application developed in android studio which helps the user to grow their skills at their own pace. The application is designed in such a way that the student or the professional will give the test and based on the performance, the system will assess their skill level and provide them with a personalized learning path.

Some important modules of Sment:

1. Main Screen (Dashboard):

The dashboard (fig 5.1) is the main screen of Sment. It has 4 main buttons, Test, Learning Path, Test History and User Profile. User has to interact with this screen for actions like selecting test, get his 
learning path and history etc.

2. Quiz Screen:

This screen (fig 5.2) is the actual test screen of the app where the user will give the test. The test questions are stored on firebase.

3. Learning Path Screen:

This screen (fig 5.3) will provide the user the learning path recommended by the system based on his performance in the test. To get a learning path, the user has to give the test. The personalized learning path will be created using content-based filtering which is a method of recommendation algorithm.

4. Backend(firebase):

Firebase provides a real-time database which act as back-end as a service. Service provides app developers an API that allows app data to be synched across clients and stored on firebase's cloud. The test data is stored in JSON format on firebase(fig 3.4).It is also used for authentication of user on Sment.

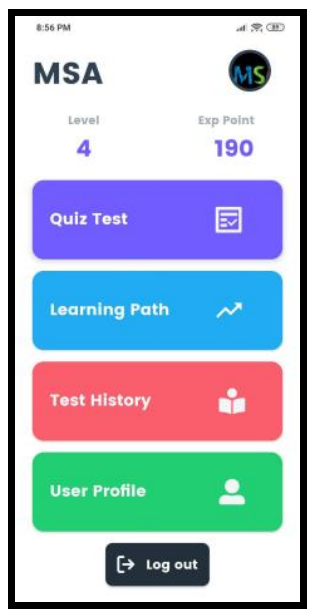

fig 3.1

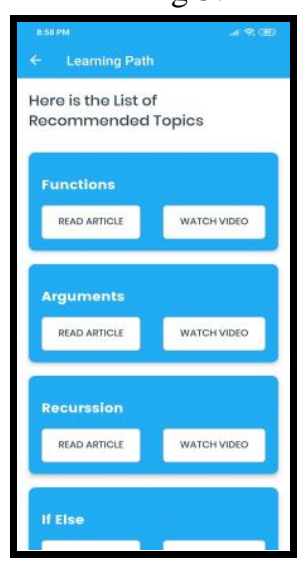

fig 3.3

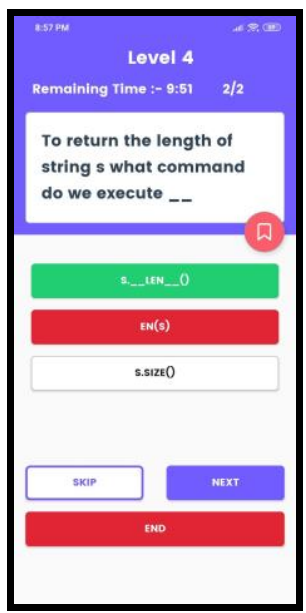

fig 3.2

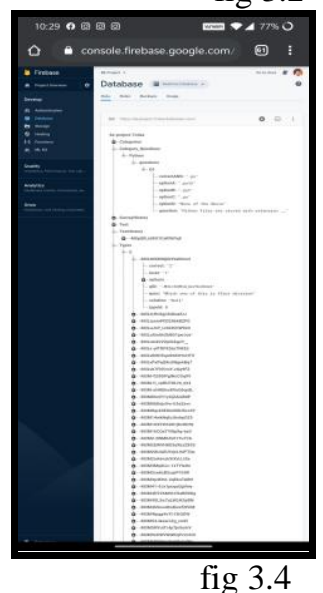

\section{CONCLUSION}

Our System will be helpful for students who are preparing for college placements because they can tune their skills and will get a brief idea about how to prepare for the company placement exam. It can also be helpful for any professional of any age to polish their programming skills and learn new technologies to keep the skills up to date. Any technology enthusiasts can also use this application.

In Future Scope, we can add many more targeted features to help the user to prepare for placements and academics or any other competitive exam and provide tutorials in the system so students don't need to roam on the internet to find notes. We can also create a desktop client for the Sment to make it platform independent. Instead of limiting it to computer science, we can also add other science fields to the app so that other science related individuals can use it to polish their skills.

\section{REFERENCE}

[1] Lynch Matthew (2018), "8 Ways Machine Learning Will Improve Education" at www.thetechedvocate.org.

[2] Sukant Khurana (2018) "Personalized learning through artificial intelligence" at medium.com.

[3] Amanda Morin (2017) "Personalized Learning: What You Need to Know" at www.understood.org.

[4] B. Yi et al., "Research on Personalized Learning Model under Informatization Environment," 2017 International Symposium on Educational Technology (ISET), Hong Kong, 2017, pp. 48-52, doi: 10.1109/ISET.2017.19.

[5] Guilherme, A. AI and education: the importance of teacher and student relations. AI \& Soc 34, 47-54 (2019). https://doi.org/10.1007/s00146-017-0693-8

[6] Er, Erkan. (2012). Identifying At-Risk Students Using Machine Learning Techniques: A Case Study with IS 100. International Journal of Machine Learning and Computing. 476-480. 10.7763/IJMLC.2012.V2.171.

[7] Ashford, S. J. (1986). Feedback-seeking in individual adaptation: A resource perspective. Academy of Management Journal, 29(3), 465-487. https://doi.org/10.2307/256219

[8] Hattie, J., \& Timperley, H. (2007). The Power of Feedback. Review of Educational Research, 77(1), 81112. https://doi.org/10.3102/003465430298487

[9] Heritage, M. (2007). Formative Assessment: What Do Teachers Need to Know and Do? Phi Delta Kappan, 89(2), $\quad$ 140-145. https://doi.org/10.1177/003172170708900210 
[10] Pellegrino, James. (2005). The Challenge of Knowing What Students Know. Measurement: Interdisciplinary Research and Perspectives.

[11] William, Dylan. (2006). Formative Assessment: Getting the Focus Right. Educational Assessment. 11. 283-289. 10.1207/s15326977ea1103\&4_7.

[12] Ibtehal Talal Nafea "Machine Learning in Education Technology" July 3rd, 2017 July 3rd 2017, Published: September 19th 2018, DOI: 10.5772/intechopen.72906

[13] Kotsiantis, S.B. Use of machine learning techniques for educational proposes: a decision support system for forecasting students' grades. ArtifIntell Rev 37, 331-344 (2012). https://doi.org/10.1007/s10462-011-9234-X 